\title{
A BIOMETRICAL ANALYSIS OF MATROCLINOUS INHERITANCE OF GRAIN WEIGHT IN RICE
}

\author{
M. F. CHANDRARATNA \\ Department of Agriculture, Peradeniya, Ceylon \\ and \\ KAN-ICHI SAKAI \\ National Institute of Genetics, Mishima, Japan
}

Received 10.ix.57

\section{INTRODUCTION}

Cytoplasmic inheritance, as expressed in differences between reciprocal crosses, occurs extensively among cryptograms and angiosperms, and is associated with extreme oögamy. Geneticists no longer consider hereditary transmission the total monopoly of the nucleus, but the mechanism of cytoplasmic inheritance is still imperfectly understood. Systems of self-propagating, extranuclear determinants or plasmagenes have been invoked by various workers (Darlington, 1939; Wright, I94I), but the possibility that, in certain instances, reciprocal differences between crosses result from the persistence in the cytoplasm of delayed nuclear effects must be conceded. The issue can be decided by an exchange of nuclei through repeated backcrossing to the male parent (Michaelis, I 954).

Striking reciprocal differences that derive from disturbances in the normal pattern of development have been the subject of much investigation. The quantitative and less spectacular expressions of matrocliny have received less attention. Quantitative matroclinous differences, however, are probably of greater significance in breeding, and possess the attraction of being more amenable to biometrical analysis. The instance of matroclinous inheritance of grain weight, which forms the subject of the biometrical analysis presented herein, was noted during the course of a study of the genetics of yield components in rice (Oryza sativa L.). The authors have been unable to find in the literature on the subject, a previous record of an attempt at the biometrical analysis of a character manifesting matroclinous inheritance.

\section{MATERIALS AND METHODS}

The rice pure lines Vellai Ilankalayan $2806 I(v)$ and Panduruwi $(p)$ were used in

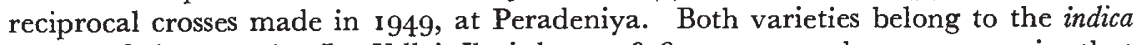
group of Oryza sativa L. Vellai Ilankalayan $2806 \mathrm{I}$ possesses the coarse grain that characterises most varieties indigenous to Ceylon. Panduruwi, which is finer grained, is a selection within a variety of obscure antecedents, but probably of foreign origin. Progenies derived from these reciprocal crosses were grown in successive generations at the Central Rice Breeding Station, Batalagoda, and the weight of one hundred grains was recorded in hybrid populations and lines. In $F_{1}$ plants, the roo-grain weight was calculated from relatively small numbers. Table $\mathrm{I}$ indicates the numbers of plants and lines investigated in various generations. 


\section{GRAIN WEIGHT IN PARENTAL AND FILIAL GENERATIONS}

Mean values of the Ioo-grain weight in parental varieties, reciprocal $\mathrm{F}_{1}$ hybrids and segregating populations are given in table $\mathrm{I}$.

TABLE I

Ioo-grain weight in parents $F_{1}, F_{2}$ and $F_{3}$

\begin{tabular}{|c|c|c|c|c|c|c|}
\hline \multicolumn{4}{|c|}{ Generation } & Notation & $\begin{array}{c}\text { Number } \\
\text { investigated }\end{array}$ & $\begin{array}{c}\text { 10o-grain weight } \\
(\mathrm{gm} .)\end{array}$ \\
\hline $\begin{array}{l}\mathrm{P}_{1}(p) \\
\mathrm{P}_{2}(v) \\
\mathrm{F}_{1}(p \times v) \\
\mathrm{F}_{1}(v \times p) \\
\mathrm{F}_{2}(p \times v) \\
\mathrm{F}_{2}(v \times p) \\
\mathrm{F}_{3}(p \times v)\end{array}$ & $\left\{\begin{array}{c}\cdot \\
\left\{\begin{array}{l}\text { No. } 25 \\
\text { No. } 31\end{array}\right. \\
\left\{\begin{array}{l}\text { No. } 25 \\
\text { No. } 31\end{array}\right.\end{array}\right.$ & 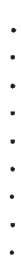 & $\begin{array}{l}. \\
\end{array}$ & $\begin{array}{l}x_{0} \\
y_{0} \\
x_{1} \\
y_{1} \\
x_{2} \\
x_{2} \\
y_{2} \\
x_{3} \\
x_{3}\end{array}$ & $\begin{array}{l}96 \text { plants } \\
31 \text { I ", } \\
5 \quad, \\
8 \quad, \\
74 \quad, \\
\text { I5 ", } \\
\text { I84 ", } \\
\text { I3 lines } \\
6 \text {," }\end{array}$ & 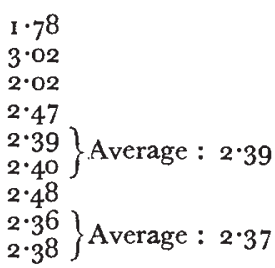 \\
\hline
\end{tabular}

The roo-grain weights of the parents were $1.78 \mathrm{gm}$. and $3.02 \mathrm{gm}$., with a mid-parental value of $2 \cdot 40 \mathrm{gm}$. The differences between reciprocal hybrids in both $\mathrm{F}_{1}$ and $\mathrm{F}_{2}$ generations indicate marked matrocliny: the Ioo-grain weights of $\mathrm{F}_{1}(p \times v)$ and $\mathrm{F}_{1}(v \times p)$ were $2.02 \mathrm{gm}$. and $2.47 \mathrm{gm}$. respectively. Reciprocal differences persisted in the $\mathrm{F}_{2}$ generation: $\mathrm{F}_{2}(v \times p)$ showed a higher value for the roo-grain weight than $\mathrm{F}_{2}(p \times v)$. In the instance of the $p \times v$ cross at least, the maternal effect tended to decline in later generations. It is evident that in the crosses that form the subject of the present investigation, grain weight is controlled not only by nuclear genes but by cytoplasmic factors.

\section{THE GENETIC MODEL}

The following genetic model which has been constructed to fit the results presented above assumes that the phenotype of the hybrid is determined primarily by its genotype, but is affected by cytoplasmic

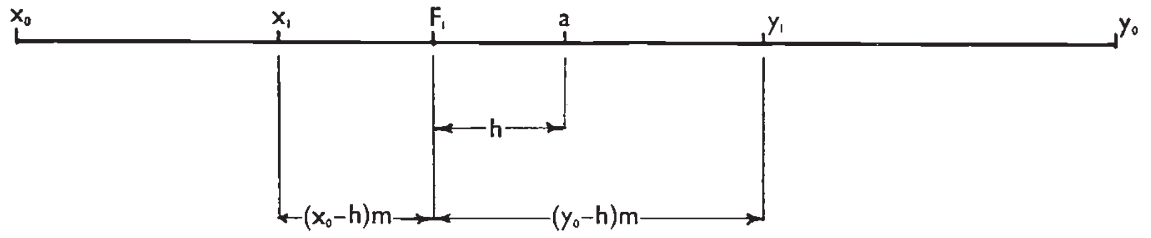

FIG.I.-Genetic model of grain-weight inheritance in reciprocal hybrids : $x_{0}$ and $y_{0}$ are the parents, $a$ is the midparental value, $h$ is the deviation due to dominance, and $m$ is a constant that provides a measure of the magnitude of the maternal effect.

factors contributed by the female parent. It is also assumed that the genotype of the female parent influences the nature of these cytoplasmic factors. Fig. I gives a diagram of the model. 
On the basis of this model, the average phenotypic value of the various hybrid populations will be:

and

$$
\left.\begin{array}{rl}
x_{1} & =a+h+\left\{\left(x_{0}-a\right)-h\right\} m \\
x_{2} & =a+\frac{h}{2}+\left\{\left(x_{1}-a\right)-\frac{h}{2}\right\} m \\
x_{n} & =a+\frac{h}{2^{n-1}}+\left\{\left(x_{n-1}-a\right)-\frac{h}{2^{n-1}}\right\} m
\end{array}\right\}
$$

$$
\left.\begin{array}{rl}
y_{1} & =a+h+\left\{\left(y_{0}-a\right)-h\right\} m \\
y_{2} & =a+\frac{h}{2}+\left\{\left(y_{1}-a\right)-\frac{h}{2}\right\} m \\
y_{n} & =a+\frac{h}{2^{n-1}}+\left\{\left(y_{n-1}-a\right)-\frac{h}{2^{n-1}}\right\} m
\end{array}\right\}
$$

$x_{n}$ and $y_{n}$ can be re-written in the following form:

$$
x_{n}=a(\mathrm{I}-m)+\frac{h}{2^{n-1}}(\mathrm{I}-m)+m x_{n-1}
$$

and

$$
y_{n}=a(\mathrm{I}-m)+\frac{h}{2^{n-1}}(\mathrm{I}-m)+m y_{n-1}
$$

The following two formulæ which are derived from (3) and (4) are functions of parental values:

$$
\begin{aligned}
& x_{n}=a\left(\mathrm{I}-m^{n}\right)+\frac{h(\mathrm{I}-m)}{2^{n-1}} \frac{\left(\mathrm{I}-2^{n} m^{n}\right)}{(\mathrm{I}-2 m)}+m^{n} x_{0} \\
& y_{n}=a\left(\mathrm{I}-m^{n}\right)+\frac{h(\mathrm{I}-m)}{2^{n-1}} \frac{\left(\mathrm{I}-2^{n} m^{n}\right)}{(\mathrm{I}-2 m)}+m^{n} y_{0}
\end{aligned}
$$

substituting $p$ for $a(\mathrm{I}-m)$ and $q$ for $h(\mathrm{I}-m)$, the following equations for securing estimates of $a, m$ and $h$ are obtained.

$$
\left.\begin{array}{l}
x_{1}: p+q+1 \cdot 78 m=2 \cdot 02 \\
y_{1}: p+q+3 \cdot 02 m=2 \cdot 47 \\
x_{2}: p+0.5 q+2 \cdot 02 m=2 \cdot 39 \\
y_{2}: p+0.5 q+2 \cdot 47 m=2 \cdot 48 \\
x_{3}: p+0.25 q+2 \cdot 39 m=2 \cdot 37
\end{array}\right\}
$$

The least squares method provides the following three simultaneous equations:

$$
\left.\begin{array}{ll}
5 p+3 \cdot 25 q+\mathrm{II} \cdot 68 m & =\mathrm{II} \cdot 73 \\
3 \cdot 25 p+2 \cdot 5625 q+7 \cdot 6425 m & =7 \cdot 5^{\mathrm{I}} 75 \\
\mathrm{II} \cdot 68 p+7 \cdot 6425 q+28 \cdot \mathrm{I} 822 m & =27 \cdot 6727
\end{array}\right\}
$$

The $c$-matrix obtained is

$$
\begin{array}{rrrrr}
c_{p p}-6 \cdot 88005^{2} & c_{q p}-\mathrm{I} \cdot \mathrm{I} 59747 & & c_{m p}-2 \cdot 536908 \\
c_{p q}-\mathrm{I} \cdot \mathrm{I} 59747 & c_{q q} 2 \cdot 236340 & & c_{m q}-0 \cdot \mathrm{I} 25802 \\
c_{p m}-2 \cdot 536908 & c_{q m}-0 . \mathrm{I} 25802 & c_{m m} & \mathrm{I} \cdot \mathrm{I} 2 \mathrm{IOIO}
\end{array}
$$


Hence :

and

$$
\left.\begin{array}{rl}
m & =0.3 \mathrm{I} 77 \pm 0.07 \mathrm{IO} \\
p & =a(\mathrm{I}-m)=\mathrm{I} \cdot 78 \mathrm{I} 5 \pm 0 . \mathrm{I} 759 \\
q & =h(\mathrm{I}-m)=-0.2734 \pm 0 . \mathrm{I} 003 \\
h & =-0.4008 \text { and } a=2.6 \mathrm{II} \mathrm{I}
\end{array}\right\}
$$

Table 2 permits the comparison of observed values with expected values for different hybrid populations derived from the above estimates.

TABLE 2

Comparison of observed values with the expected values based on the genetic model

\begin{tabular}{|l|l|l|}
\hline & Observed & Expected \\
\hline & & \\
\hline$x_{1}$ & $2 \cdot 02$ & $2 \cdot 0736$ \\
$y_{1}$ & $2 \cdot 47$ & $2 \cdot 4675$ \\
$x_{2}$ & $2 \cdot 39$ & $2 \cdot 3036$ \\
$y_{2}$ & $2 \cdot 48$ & $2 \cdot 4288$ \\
$x_{3}$ & $2 \cdot 37$ & $2 \cdot 445 \mathrm{I}$ \\
\hline
\end{tabular}

Comparison of observed and expected values in different hybrid populations in table 2 using the standard errors of estimated values demonstrates the adequacy of the genetic model.

\section{PARTITIONING OF VARIANCE COMPONENTS IN HYBRID POPULATIONS}

The methods and notation of Mather (1949) have been used in the partitioning of components of variation in various hybrid populations. The results are presented in table 3 .

The observed variance and covariance values in different hybrid populations and the values expected on the basis of estimated $\mathrm{D}, \mathrm{H}$ and $E$ values described later are presented in table 4.

Equations for deriving estimates of $\mathrm{D}, \mathrm{H}$ and $\mathrm{E}$ are as follows:

$$
\left.\begin{array}{ll}
\mathrm{E}_{1} & =0.0072 \\
\frac{1}{2}(\mathrm{I}-m)^{2} \mathrm{D}+\frac{1}{4}(\mathrm{I}-m)^{2} \mathrm{H}+\mathrm{E}_{1} & =0.0562 \\
\frac{1}{4}(\mathrm{I}-m)^{2} \mathrm{D}+\frac{1}{8}(\mathrm{I}-m)^{2} \mathrm{H}+\mathrm{E}_{1} & =0.0247 \\
\frac{1}{2}(\mathrm{I}-m)^{2}(\mathrm{I}+m)^{2} \mathrm{D}+\frac{\mathbf{1}}{16}(\mathrm{I}-m)^{2}(\mathrm{I}+2 m)^{2} \mathrm{H}+\mathrm{E}_{2} & =0.04 \mathrm{I}^{2} \\
\frac{1}{8}(\mathrm{I}-m)^{2} \mathrm{D}+\frac{1}{16}(\mathrm{I}-m)^{2} \mathrm{H}+\mathrm{E}_{1} & =0.026 \mathrm{O} \\
\frac{1}{2}(\mathrm{I}+m)(\mathrm{I}-m)^{2} \mathrm{D}+\frac{1}{8}(\mathrm{I}+2 m)(\mathrm{I}-m)^{2} \mathrm{H} & =0.033^{2}
\end{array}\right\}
$$

Substituting $0 \cdot 3 \mathrm{I} 77$ for $m$ (see (9)), and $\mathrm{E}_{2}$ for $\frac{\mathrm{E}_{1}}{n}$ (where $n=42 \cdot 20$, the harmonic mean of the number of individuals included in each $\mathrm{F}_{3}$ line), we derive the following three simultaneous equations by the least squares method:

$$
\left.\begin{array}{l}
0.328532 \mathrm{D}+0.096 \mathrm{I} 96 \mathrm{H}+0.4 \mathrm{I} 692 \mathrm{IE}_{1}=0.044425 \\
0.096 \mathrm{I} 96 \mathrm{D}+0.032890 \mathrm{H}+0.2055 \mathrm{I}_{5} \mathrm{E}_{1}=0.0 \mathrm{I} 5 \mathrm{I} 24 \\
0.4 \mathrm{I} 692 \mathrm{I} \mathrm{D}+0.205 \mathrm{I}_{5} \mathrm{H}+4.000562 \mathrm{E}_{1}=0.1 \mathrm{I} 084
\end{array}\right\}
$$


TABLE 3

Components of variation in various hybrid populations

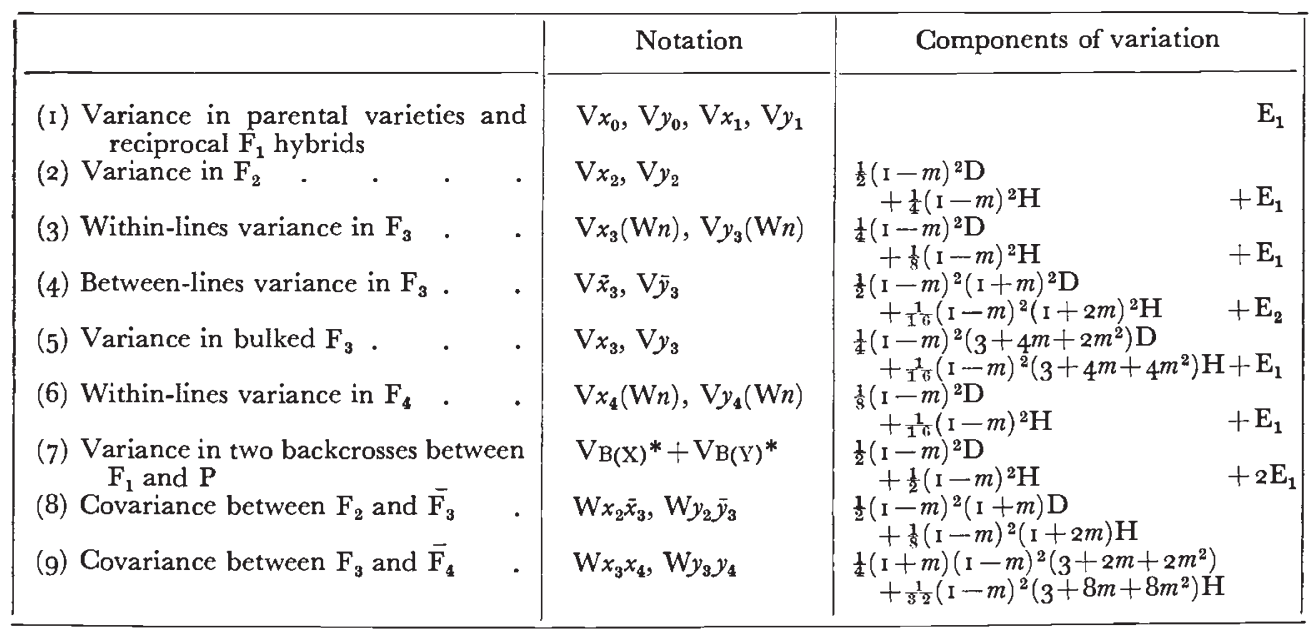

* Backcrosses fall into two groups, $X$ and $Y ; V_{B}(x)+V_{B(y)}$ represents the sum of the variance of an $\mathrm{X}$-group cross and the variance of a $\mathrm{Y}$-group cross. The group $\mathrm{X}$ consists of backcrosses of $\mathrm{F}_{1}$ to $x_{0}$; backcrosses to $\mathrm{Y}_{0}$ compose group $\mathrm{Y}$ :

$$
\mathrm{X} \ldots \ldots\left\{\begin{array} { l } 
{ x _ { 0 } \times y _ { 1 } } \\
{ y _ { 1 } \times x _ { 0 } } \\
{ x _ { 1 } \times x _ { 0 } } \\
{ x _ { 0 } \times x _ { 1 } }
\end{array} \quad \mathrm { Y } \ldots \left\{\begin{array}{l}
y_{0} \times y_{1} \\
y_{1} \times y_{0} \\
x_{1} \times y_{0} \\
y_{0} \times x_{1}
\end{array}\right.\right.
$$

TABLE 4

Observed and expected values of variance and covariance in parental varieties and hybrid populations

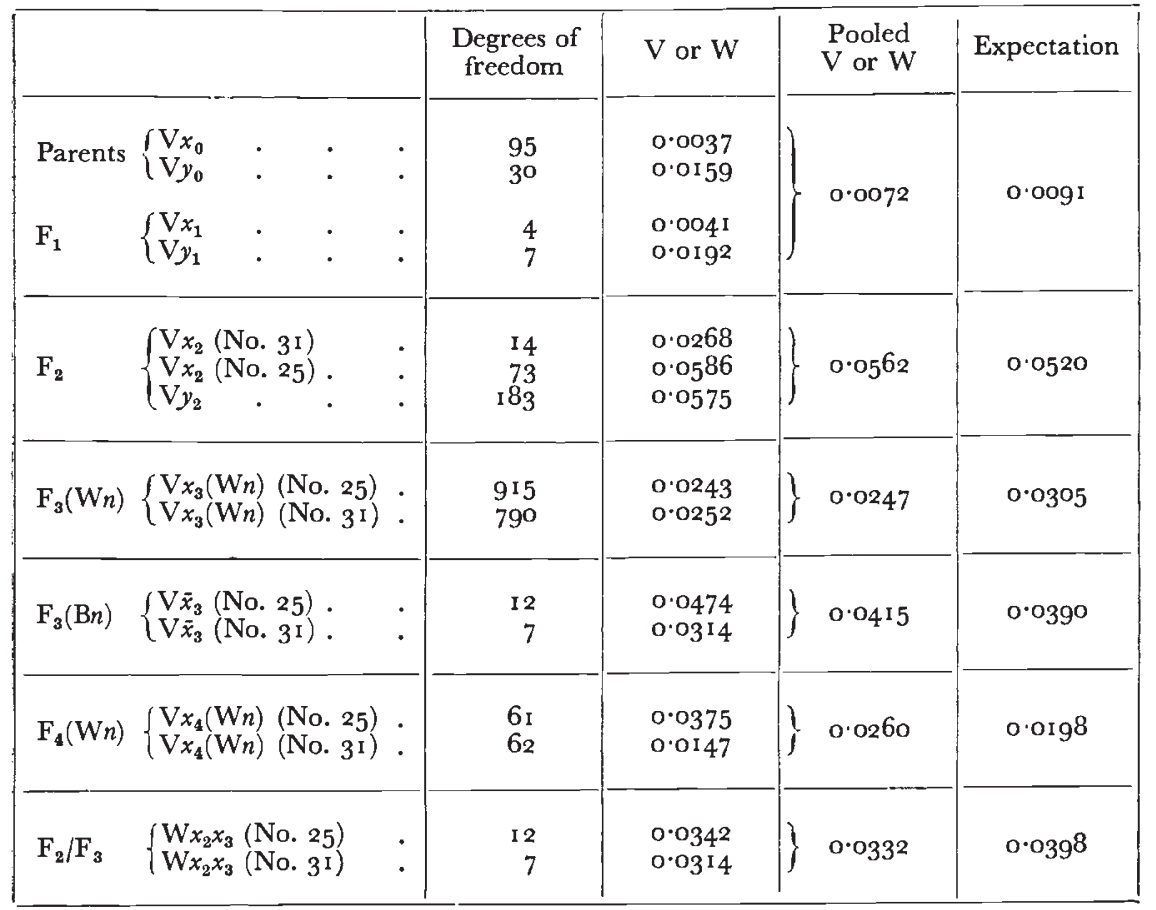


The $c$-matrix obtained is:
$C_{\text {DD }} \quad 27 \cdot 673973$
$\mathrm{C}_{\mathrm{HD}}-9 \mathrm{I} \cdot 308962$
$\mathrm{C}_{\mathrm{ED}} \quad \mathrm{I} \cdot 659270$
$\mathrm{C}_{\mathrm{DH}}-9 \mathrm{I} \cdot 308962$
$\mathrm{C}_{\text {HH }} 344 \cdot 38553 \mathrm{I}$
$\mathrm{C}_{\mathrm{EH}}-7 \cdot 50896 \mathrm{I}$
$\mathrm{C}_{\mathrm{DE}} \quad \mathrm{I} \cdot 659270$
$\mathrm{C}_{\mathrm{HE}}-7 \cdot 50896 \mathrm{I}$
$\mathrm{C}_{\mathrm{EE}} \quad 0 \cdot 425044$

Estimated values $\mathrm{D}, \mathrm{H}$ and $\mathrm{E}_{\mathbf{1}}$ are:

$$
\left.\begin{array}{l}
\mathrm{D}=0 \cdot 0404 \pm 0 \cdot 039^{2} \\
\mathrm{H}=0 \cdot 2879 \pm 0 \cdot 1383 \\
\mathrm{E}_{1}=0 \cdot 009 \mathrm{I} \pm 0 \cdot 0049
\end{array}\right\}
$$

\section{HERITABILITY}

Components of variation in $F_{2}$ populations provide two estimates. of heritability. The ratio of genetic variance to total variance measures. heritability in the broad sense.

$$
\frac{\frac{1}{2}(\mathrm{I}-m)^{2} \mathrm{D}+\frac{1}{4}(\mathrm{I}-m)^{2} \mathrm{H}}{\frac{1}{2}(\mathrm{I}-m)^{2} \mathrm{D}+\frac{1}{4}(\mathrm{I}-m)^{2} \mathrm{H}+\mathrm{E}_{1}}=0 \cdot 7692
$$

Heritability in the narrow sense is defined as the ratio of additive genetic variance to total variance.

$$
\frac{\frac{1}{2}(\mathrm{I}-m)^{2} \mathrm{D}}{\frac{1}{2}(\mathrm{I}-m)^{2} \mathrm{D}+\frac{1}{4}(\mathrm{I}-m)^{2} \mathrm{H}+\mathrm{E}_{1}}=0.4009
$$

The regression of $F_{3}$ lines on $F_{2}$ parents furnishes an estimate of heritability intermediate between the above two values.

$$
b_{\mathrm{F}_{3} / \mathrm{F}_{2}}=\frac{\mathrm{W}_{\overline{\mathrm{F}}_{3} / \mathrm{F}_{2}}}{\mathrm{~V}_{\mathrm{F}_{2}}}=0.5907
$$

The correlation coefficient of $F_{2}$ individuals and $F_{3}$ lines is

$$
r_{\mathrm{F}_{2} / \mathrm{F}_{3}}=\frac{\mathrm{W}_{\overline{\mathrm{F}}_{3} / \mathrm{F}_{2}}}{\sqrt{\overline{\mathrm{V}}_{\mathrm{F}_{2}} \cdot \mathrm{V}_{\mathrm{F}_{3}}^{-}}}=0.6874
$$

\section{NUMBER OF EFFECTIVE FACTORS}

The following calculation of the number of effective factors assumes (a) that all the genes have equal additive effects, and $(b)$ that one parent carries all the plus allelomorphs and the other parent all the minus allelomorphs.

$$
k=\frac{\left[\frac{1}{2}\left(\overline{\mathbf{P}}_{1}-\overline{\mathrm{P}}_{2}\right)\right]^{2}}{\mathrm{D}}=9.5 \mathrm{I}
$$

The number of effective factors is estimated to be about ten. It should, of course, be remembered that the assumptions implicit in the formula are unlikely to be completely justified.

\section{DISCUSSION}

A survey of the voluminous literature on cytoplasmic inheritance is not attempted in the following discussion: for reviews, reference may be made to Caspari (1948) and Michaelis (1954). 
The results relating to matroclinous inheritance in the cross reported in this communication fit the hypothesis of extranuclear determinants transmitted to the hybrid through the cytoplasm of the female parent. The effect of these cytoplasm-borne determinants is to shift the phenotypic expression of the progeny towards that of the female parent. The direction of shift suggests that the maternal genotype influences the nature of the determinants.

The agreement between observed and expected values in tables 2 and 4 demonstrates the adequacy of the genetic model proposed in this paper.

The value of $m$, the coefficient of maternal effect, in grain-weight inheritance in the cross reported herein is 32 per cent. An investigation of matroclinous effects in a wide range of crosses would elucidate the nature of the cytoplasmic determinants involved.

The relation of the matroclinous inheritance of a character to its heritability is of considerable interest. Formulæ (I3) and (I4) show that the maternal effect depresses heritability. For instance, heritability in the narrow sense is given by the equation:

$$
h^{2}=\frac{\frac{1}{2}(\mathrm{I}-m)^{2} \mathrm{D}}{\frac{1}{2}(\mathrm{I}-m)^{2} \mathrm{D}+\frac{1}{4}(\mathrm{I}-m)^{2} \mathrm{H}+\mathrm{E}_{1}}=\frac{\frac{1}{2} \mathrm{D}}{\frac{1}{2} \mathrm{D}+\frac{1}{4} \mathrm{H}+\mathrm{E}_{1} /(\mathrm{I}-m)^{2}}
$$

If $m$ assumes a value between $\mathrm{I}$ and o (i.e. $\mathrm{I}>m>0$ ), $\frac{\mathrm{E}_{1}}{(\mathrm{I}-m)^{2}}$ becomes larger than $\mathrm{E}_{1}$, and accordingly the value of $h^{2}$ falls.

If the maternal effect is complete, the heritability value will be zero exactly as in a homozygous line. An illustrative example in which $\mathrm{D}, \mathrm{H}$ and $\mathrm{E}$ all assume the value of unity is given in table 5 .

TABLE 5

The relation between maternal effect and heritability value

\begin{tabular}{|l|c|}
\hline$m$ & $\begin{array}{c}\text { Heritability } \\
\text { (per cent.) }\end{array}$ \\
\hline 0 & $28 \cdot 6$ \\
0 & $25 \cdot 2$ \\
$0 \cdot 1$ & $21 \cdot 6$ \\
$0 \cdot 2$ & $17 \cdot 9$ \\
$0 \cdot 3$ & $14 \cdot 2$ \\
$0 \cdot 4$ & $10 \cdot 5$ \\
$0 \cdot 5$ & $7 \cdot 1$ \\
0.6 & $4 \cdot 2$ \\
$0 \cdot 7$ & $1 \cdot 9$ \\
0.8 & $0 \cdot 5$ \\
$0 \cdot 9$ & 0 \\
\hline $1 \cdot 0$ & \\
\hline
\end{tabular}

It is noteworthy that if $\mathrm{E}_{1}=0$, i.e. if the character under investigation is completely free of environmental variation, the maternal effect would not influence heritability. 
The effect of matroclinous inheritance on the mean value of reciprocal-hybrid populations warrants consideration. Table 6 presents a computation of the difference in mean values of grain weight between the two reciprocal-hybrid populations, $(p \times v)$ and $(v \times p)$, over the generations $F_{1}$ to $F_{10}$. It will be noted that with successive selfings, the difference declines rapidly.

TABLE 6

Expected grain weights in reciprocal-hybrid populations

\begin{tabular}{|c|c|c|c|}
\hline $\begin{array}{c}\text { Filial } \\
\text { generation }\end{array}$ & $h \times v$ & $v \times h$ & Difference \\
\hline $\begin{array}{l}\mathrm{F}_{1} \\
\mathrm{~F}_{2} \\
\mathrm{~F}_{3} \\
\mathrm{~F}_{4} \\
\mathrm{~F}_{5} \\
\mathrm{~F}_{8} \\
\mathrm{~F}_{7} \\
\mathrm{~F}_{8} \\
\mathrm{~F}_{8} \\
\mathrm{~F}_{10}\end{array}$ & $\begin{array}{l}2 \cdot 0736 \\
2 \cdot 3036 \\
2 \cdot 4451 \\
2 \cdot 5249 \\
2 \cdot 5674 \\
2 \cdot 5882 \\
2.5959 \\
2 \cdot 6034 \\
2 \cdot 60819 \\
2 \cdot 60964\end{array}$ & $\begin{array}{l}2 \cdot 4675 \\
2 \cdot 4288 \\
2.4848 \\
2.5375 \\
2.5714 \\
2 \cdot 5896 \\
2.5963 \\
2 \cdot 6035 \\
2.60832 \\
2 \cdot 60966\end{array}$ & $\begin{array}{l}0.3939 \\
0.1252 \\
0.0397 \\
0.0126 \\
0.0040 \\
0.0014 \\
0.0004 \\
0.0001 \\
0.00004 \\
0.00002\end{array}$ \\
\hline
\end{tabular}

The genetical meaning of the following two formulæ may now be examined:

and

$$
\mathrm{X}_{n}=a\left(\mathrm{I}-m^{n}\right)+\frac{h(\mathrm{I}-m)}{2^{n-1}} \frac{\left(\mathrm{I}-2^{n} m^{n}\right)}{(\mathrm{I}-2 m)}+m^{n} x_{0}
$$

$$
\mathrm{Y}_{n}=a\left(\mathrm{I}-m^{n}\right)+\frac{h(\mathrm{I}-m)}{2^{n-1}} \frac{\left(\mathrm{I}-2^{n} m^{n}\right)}{(\mathrm{I}-2 m)}+m^{n} y_{0}
$$

In these two formulæ,

(a) if $m=\mathrm{o}$ (i.e. there is no maternal effect), then $\mathrm{X}_{n}=\mathrm{Y}_{n}$ $=a+\frac{h}{2^{n-1}}$;

(b) if $m=\mathrm{I}$ (i.e. the maternal effect is complete), then in any hybrid generation, $\mathrm{X}_{n}=\mathrm{X}_{0}$ and $\mathrm{Y}_{n}=\mathrm{Y}_{0}$;

(c) if $m$ assumes a value between $\mathrm{o}$ and I (i.e. I $>m>0$ ), the difference between reciprocal hybrid populations attributable to the maternal effect will decrease in successive generations (see table 6).

In the formulæ (5) and (6), if $n \rightarrow \infty$, then $x_{n}$ and $y_{n}$ approximate $a$. The difference between reciprocal hybrids is given by the equation,

$$
y_{n}-x_{n}=m^{n}\left(y_{0}-x_{0}\right)
$$

In this equation, $m^{n}\left(y_{0}-x_{0}\right)$ approaches zero if $n \rightarrow \infty$, because $m$ has a value between $O$ and $I$. 


\section{SUMMARY}

I. Grain weight in rice (Oryza saliva L.) has been found to exhibit matroclinous inheritance.

2. A genetic model has been constructed on the assumption that a system of extranuclear determinants can $(a)$ interact with the genotype, (b) be transmitted to the progeny through the female cytoplasm, and $(c)$ influence the phenotypic expression of the progeny for one generation.

3. Comparison of the experimental results with expected values computed on the basis of the above-mentioned assumption demonstrates the sufficiency of the hypothetical model.

4. Formulæ relating to grain weight in successive filial generations have been worked out, and components of variation have been partitioned by the methods of Mather (I949).

5. The value of $m$, the coefficient of maternal effect, is 32 per cent.

6 . Heritability in the broad sense assumes a value of 0.77 ; heritability in the narrow sense has a value of 0.40 .

7. The number of effective factors approximates ten.

8. The genetical meaning of matroclinous inheritance is discussed.

Acknowledgment.-We are deeply grateful to $\mathrm{Mr} \mathrm{J}$. J. Niles for valuable assistance in the hybridisation work and in the recording of data.

\section{REFERENCES}

CASPARI, C. 1948. Cytoplasmic inheritance. Advances in Genet., 2, I-66.

DARLington, C. D. 1939. The Evolution of Genetic Systems. University Press, Cambridge.

MATHER, x. I949. Biometrical Genetics. Methuen, London.

michaelis, P. 1954. Cytoplasmic inheritance in Epilobium. Advances in Genet., $6,288-394$.

Wright, s. I94I. The physiology of the gene. Physiol. Rev., 2r, 487-527. 